\title{
The Impact of Building Information Modelling (BIM) for Contractor Costing in Offsite Construction Projects in the UK
}

\author{
Tochukwu MOSES ${ }^{1,4 *}$, David HEESOM ${ }^{2}$ and David OLOKE ${ }^{3}$ \\ ${ }^{1}$ Doctoral Researcher, School of Architecture and Built Environment, University of \\ Wolverhampton, United Kingdom \\ ${ }^{2}$ Reader in BIM, School of Architecture and Built Environment, University of Wolverhampton, \\ United Kingdom \\ ${ }^{3}$ Senior Research and Development Consultant, School of Architecture and Built \\ Environment, University of Wolverhampton, United Kingdom \\ ${ }^{4}$ Corresponding author's e-mail: t.g.moses@icloud.com
}

\begin{abstract}
It is clear that challenging economic times inspire innovative abilities and solutions in the construction industry. In particular many of these innovations focus on cost implications, saving project time, reducing or eliminating waste, increasing productivity or redefining value. There is increasing pressure in the UK construction industry for new construction innovations, technology and processes with ability to lever a significant impact relative to disrupting the existing status quo; creating solutions that promote construction efficiencies deploying means to exploiting offsite construction approaches. The increased concern and challenge globally is that as knowledge and experience grows, the offsite manufacturers and suppliers are expected to demonstrate absolute innovative solutions that will heighten the proportion of project value being delivered through the use of offsite solutions on the bases that it makes sound project and business sense. Unparalleled huge cost saving benefits to clients and end users which is more than just creating a model is yet to be realized.
\end{abstract}

BIM has initiated a paradigm shift from the traditional 2D design practices, as development of models span through the combination of 3D (graphical modeling), 4D (time modeling) and 5D (cost modeling) (Deutsch R., 2011). With the advent of BIM as a significant benefit and a new way of working within the UK construction industry, Offsite Manufacturers, Suppliers, Design for Manufacture and Assembly (DFMA) innovation and Contractors of projects are yet to see BIM as a mainstream integrated and sustainable construction option to enhance construction efficiency (HM Government, 2012). Therefore, this study examines potentials of BIM strategy and capabilities towards cost reduction and its ability to harness better construction efficiency relative to offsite construction and offsite productivity cost in light of recent literatures.

Key Words: Building Information Modelling (BIM), Contractor Costing, Offsite Construction, Cost. 


\section{INTRODUCTION}

$\mathrm{BIM}$ is a digital representation of physical and functional characteristics of a facility. As such it serves as a shared knowledge resource for information about a facility forming a reliable basis for decision during its lifecycle from (earliest conception) to demolition (Eastman C., et al 2011; RICS, 2014). According to Qing Lin, Tao Gao, Jianping Wang (2011) is seen as an open standards based information repository for the facility lifecycle. It is also a tool for visualizing and coordinating Architecture, Engineering and Construction (AEC) work to avoid errors and omissions. BIM in most simple terms is the utilization of a database infrastructure to encapsulate built facilities with specific viewpoints of stakeholders.

By 2016, the UK Government will require fully collaborative 3D Level 2 BIM (with all project and asset information, documentation and data being electronic) as a minimum (Cabinet Office, 2011). This is because BIM ensures best value at every stage of the project life-cycle. Building Information Modelling (BIM) technology has proven to be a tool for building models in Architecture, Engineering and Construction (AEC). The designed building object based data model supports construction, fabrication (offsite manufacturing), procurement activities and costing (Alshawi M., and Faraj I., 2002). Currently contractors and subcontractor trades are realising the huge benefits involved in BIM implementation on projects which includes improved collaboration within the project team, improved interoperability, on time completion, cost reduction, information management process and product, reliable decision base, clash detection, conflict resolution, data management, quality control, construction sequencing etc. There are still concerns in the UK construction industry influenced by resistance to change and inability to adapt to the new innovative working process. BIM is a multidimensional model $\{3 \mathrm{D}, 4 \mathrm{D}$ (time) and 5D (cost) $\}$ in which a virtually unlimited range of visual and non-visual project and building related information is tagged or attached to each model element as a collection of attributes (Bloomberg, et al., 2012).

\section{BIM AND FABRICATORS}

Economies of prefabrication supports the larger proportions of building products and systems that is manufactured offsite (Eastman C., et al., 2011). The ever increasing complexities of building facilities require custom design and fabrication of "engineered to order" (ETO) components (Hardin, B., 2009) which includes but not limited to structural steel, bathroom and toilet units, precast concrete structures and architectural facades, curtain walls of various types, mechanical, electrical and plumbing (MEP) systems, roof trusses, reinforced concrete tilt-up panels etc - sophisticated engineering with ETO components demands an expected degree of collaboration within design team to ensure fitness of building components with no installation or out-of-scale interference and to avoid system interface issues. Design, information and data management, coordination with 2D CAD systems is error-prone process, labour and lead time and relies on long cycle times (Bew and Underwood, 2009). BIM resolves these concerns by supporting and improving virtual construction of components, reviews coordination among all building systems prior to product production. BIM supports all supply chain special trades (contractors, fabricators etc) for numerous derivable benefits enhanced marketing and rendering through visual images, automated 5D estimation, reduced lead time for detailed design (working designs) and productions. Exposing and removing 
design coordination errors, thereby lowering engineering and detailing costs; improved preassembly and prefabrication, driving automated data for manufacturing technologies (Eastman, C., 2008). Clear, accurate and precise information is basic to the flow of products in any supply chain. BIM has the capacity to revolutionize supply chain process within the building component fabricating industry through 3D improved visual models, data accuracy, information management, 5D automated cost estimating and thereby enabling leaner construction methods if well harnessed within an organization's department. Never forget that BIM is as good and weak as the people or organization implementing or using it - meaning the success of any BIM adoption and consequent implementation depends on the skill and goodwill of the people tasked with using the technology. In order words the degree and depth of this process changes is directly proportional to the degree at which the building information models developed by participating organizations are integrated (Eastman, C., et al., 2011). BIM provides platform for fabricators that supports parametric and bespokable parts and relationships, creating seamless interfaces for information management, improves internal process, with ability to import product model information from designers' BIM platforms (Hardin, B., 2009). It offers sustainable information for better model visualization and supports data export in suitable and adoptable formats for automation of fabrication tasks using computer numerically controlled (CNC) machinery. BIM supports the whole collaborative process of design development, detailing and integration in fabrication organizations. Using BIM for fabrication lends itself to an integrated process because it would not just be feasible without early involvement of fabricators and subcontracting teams.

\section{PRODUCT MANUFACTURERS AND BIM FOR OFFSITE}

Offsite Manufacturing (OSM) is defined as the production of parts of a structure from a location that is different than the location of the overall structure - providing the benefits such as higher speed, enhanced quality, higher tolerances, lower costs and reduced labour re-works on site, presently it is a general belief that the expected rapid growth in construction products will be initiated by automated offsite activities facilitated by BIM (Goulding, et al., 2012; Juhola, 2011). The development of BIM enabled Design for Manufacture and Assembly (DFMA) as a mainstream integrated and sustainable construction option and to enhance construction efficiency (HM Government, 2012). Design for Assembly (DFA) is the method of design of the product for ease of assembly and it's a tool that supports the project design teams to design products that will transit to productions at a minimal cost, focusing on the number of parts, handling and ease of assembly while design for manufacture (DFM) is the method of design for ease of manufacturing of the collection of parts that will form the product after assembly. It's for the selection of the most cost effective material and process for production in the early stages of product design. Design for Manufacture and Assembly are presently seen as a single methodology in offsite construction.

Increased advances in digital engineering are revolutionizing the UK construction industry with a realization that the Building Information Modelling (BIM) is more than just creating a model. BIM is about unveiling opportunities, knowledge and insight, thereby creating a generic platform for greater sustainable and efficient solutions for the product manufacturers. BIM should be taken beyond the traditional geometrical and asset data focus to capture time 
and cost benefits, generating unequal client and end user benefits over the lifetime of building and infrastructure. BIM early adopters, working with the Ministry of Justice (MOJ) and Highways Agencies, aligned into focus the hidden benefits of Lean Construction, DFMA and Offsite construction techniques (MOJ, 2013). Publishing the forward pipelines of projects and the capability to develop innovative solutions through widespread adoption of BIM, the industry has gained the platform to working with industry clients to develop innovative approaches to solve common problems.

\section{UK CONSTRUCTION INDUSTRY ENGAGEMENT WITH CONSTRUCTION PRODUCT MANUFACTURES}

Offsite construction has been a significant development within the building sector of the UK construction industry in the past decades. Going by value, the UK construction outputs and manufacturers are significant contributors to the overall efficiency output of the industry representing up to $40 \%$ of the construction products (Pan and Sidwell, 2011). To support the success of the current BIM programme, offsite product producers are ready to supply BIM data induced products that could support a seamless flow of data throughout the project life cycle. The UK Construction Product Association is fully ready to engage with the BIM programme and is deploying BIM strategic programme to coordinate product manufacturers to break status quo and become consistent in producing quality data. 'The Construction Product Association is fully committed to helping its members play their part in building up the UK's BIM capabilities through publishing guidance and working with others such as the National BIM Library. Early adopters in the products sector, both companies and sector trade associations, are already committing resources to ensure their products are BIM enabled. If Government and contractors water down the commitment to buy BIM enabled products or retreat into proprietary standards, then producers will see reduced or commercial advantage in investing in BIM' (HM Government, 2012).

\section{BIM AND TRADITIONAL COST ESTIMATING}

Building Information Modeling (BIM), is a 3D, 4D or 5D digital construction design tool used for sharing information between designers, clients, owners, quantity surveyors, builders, estimators and any other stakeholders in a particular project (Howard R., and Bjork B. C., 2008). It brings with it both great benefits and a few challenges in regards to cost estimation. BIM as a database of components in the design and construction of a building, can quantify accurately all the necessary materials required for construction while reducing greatly the margin for error (Haque and Mishra, 2007). The traditional estimating methods and the estimator would rely solely on the plans and specifications to make the determinations of what is required. With the multi-dimensional aspect of BIM, and the file sharing capabilities, everyone is able to see exactly what is contained in the project from a single dimensional image. This sharing feature is a huge improvement over traditional methods. BIM is capable of providing the detailed design elements and quantifications needed by today's estimators and quantity surveyors (Mena, et al., 2010). Typically, cost estimating done from quantification of components was very time consuming: counting, checking and recounting. 
The counts from one firm could vary greatly due to human error and would carry over right through to the construction bid. These errors could prove quite costly if a job was awarded to a low bidder with incorrect counts on a high cost item. But with a model of the completed project, these oversights are rare and provide for a more accurate estimate and consistency from one estimator to another.

BIM provides the estimator the ability to generate material surveys and cost estimates from conception through completion, with accuracy that can only be gained through a dimensional model (Kraus, et al., 2007). Building information modeling takes into consideration the overall life of the building as well its future maintenance and use. This is helpful in preventing the equivalent product being accepted as a substitution for specified materials in the estimation, when the properties are actually different and building integrity would be compromised. BIM is an asset to the world of estimating as well as a landmark innovation in the building industry. Professional estimators know there is more to cost estimating in BIM than simple automation of estimating from objects to spreadsheets. 'Building Information Models are formed of intelligent and multi-dimensional objects; these being objects containing information about the element they are representing, such as quantity and specification details (Azhar and Brown, 2009). Through this, BIM enables automatic quantification (Deutsch, 2011) and the production of schedules (Woo, 2007), which will largely eliminate the need for manual take-off of buildings during estimating. In addition, design data is interrelated, and therefore an alteration of one element instantly updates anything affected by the change (Sylvester and Dietrich, 2010)' (Thurairajah N., et al 2013). Cost estimators also understand the challenges and obstacles beyond the technology that must be overcome if cost estimating is to become a viable dimension of BIM

One convention deployed by estimators in the traditional process is in identifying the expected accuracy range of an estimate based on the level of project definition. In the traditional process, the project plans and specifications were the primary means by which this was determined, and as such, there was a direct correlation between the project's level of definition and the expected accuracy of an estimate. It is reasonable to expect a similar convention exists in BIM, and that as BIM contains more project definition, it also impacts the potential accuracy of an estimate. The difference in BIM, though, is in how a designer creates the objects for project 'plans,' and specifications now have an impact on the estimate.

The method or sequence by which a designer created plans and specs in the traditional formats did not impact the estimate because the information relevant to an estimate was an overlay by the estimator and external to the graphical representation. In the traditional process, the estimator managed the information from these documents and extracted, organized, and used the information as best suited to accomplish the task of estimating. However, with BIM the point of organizing information shifts as more of it begins in the design model phase. Model objects are rich with the information estimators need to create a cost estimate, and if this information is to be used by estimators, then there is a point where the estimator's process should filter into the information management during design (Pennanen et al., 2011). 
The development of a model includes the graphical representation of data-rich objects. The primary purpose of the design model is to convey design intent. However, each of the objects inserted are available now for future extraction by other stakeholders. The difference in BIM is that from an estimator's perspective, the development of a model is about the information associated with the objects and the input process for this information. This aspect of BIM is a significant shift in paradigm from which the estimator previously worked. 'Woo (2007) points out, it will be essential that design information is correct in the first place because information extracted from the model is only ever as good as that inputted. According to McCuen (2008) estimators with an adequate BIM understanding can benefit from the 5D BIM function and automatic quantification, by creating quicker estimates. This should lead to increased client satisfaction as they are receiving earlier real time economic feedback on the alternatives available (Pennanen et al., 2011), whilst having a greater understanding of the likely cost influences of design decisions (Deutsch, 2011)' (Thurairajah N., et al 2013). It is crucial that the estimator has confidence that the information is a valid representation of the object beyond the model to physical reality. This is new in the world of estimating and is challenging estimators as they work within this new paradigm.

\section{D BIM BENEFITS FOR PRODUCT MANUFACTURERS}

A shift from either a paper based drawing or digitally produced drawing to a building model has a diverse benefit - automatic consistent drawings, improved support for design analysis, cost savings, improved scheduling approaches, identification and removal of 3D spatial conflicts, more accurate preparation for bill of materials. 3D visuals are possible for product manufacturers with increased capacity, efficiency and productivity. BIM could help improve manufacturer's working processes and its workflow used to streamline office base side of production which in turn improves the entire product manufacturing processes. BIM improves the speed of production process thereby reducing the bottlenecks especially when a factory is waiting for jobs to come through; integrating BIM into that office base process speeds up production process in order words keeping the lead time short (Hannon, 2007). Production time is improved, turn over increased and this effectively saves some working weeks (which translates into huge overall cost savings). Another benefit of digital and information rich BIM environment to product manufacturers is the generation of 3D models to scale as against hand drawing which is scale accuracy deficient. BIM generates the work order sheet and the cutting sheet (partition, length, width, height etc), populating the information from each component into a cutting sheet. Multiple views of each component become possible checking the scale as work progress and if it does not fit, it can be amended accordingly (Sylvester and Dietrich, 2010). Errors on the actual work order side can be checked and should be completely cut-out by the process. The digital shift is not just in production but across the whole business especially marketing (literatures, advertising, building product directories) and as a result save cost. BIM improves the internal process of a manufacturing company, supporting the clearly set objectives and goals for BIM investment and improving product data handling to be quicker, better and in a digital way of handling product data. The outlined BIM benefits above for fabricators in offsite construction business and their design service providers has dissolved the argument by many firms and manufacturing organizations regarding the impact of initial set up BIM costs. Additional cost of purchasing new systems, retraining staff, developing new 
procedures, cost of technical expertise, costs of organizing protocols, managing a network server to store and access BIM model on project outcomes: it is easy to reason that the BIM benefits to the manufacturers do not measure up. However according to Bew and Underwood (2009), most construction professionals and organizations who are involved in BIM implementation process have found out as outlined above the positive significant impact of the set-up cost associated with the transition on the construction document level (document productivity benefits). Even the initial transition to produce consistent drawings from a model makes the transition worthwhile (Eastman, C., et al., 2011).

\section{CONCLUSION}

Information that populates BIM model definitely informs the analyses the Cost Estimator or Quantity Surveyor (QS) will do, so the more accurate the information the more reliable the outcome. This study in light of recent literatures examined, has shown that the adoption of Building Information Modelling (BIM) by offsite manufactures (OSM) is anticipated to influence and impact on the construction workflow and the thinking within the UK Construction Industry.

5D BIM is improving the capital and whole of life cost outcome through a major performance metric. Its supporting to drive a major step change in the increased productivity of a construction processes with quality improvements in the associated products and reduction in costs as well. 5D BIM is a communication tool that allows QS's and Estimators to collaborate more closely with designers and owners throughout the development of design and construction to actively drive better costs and whole-of- life outcomes. The active collaboration it generates allows the supply chain to see beyond their own activities to a more holistic view of the client's objective.

\section{REFERENCES}

Alshawi M., and Faraj I., (2002) Integrated Construction Environments: Technology and Implementation. Construction Innovation, 2, 33-51.

Azhar, S. \& Brown, J. (2009) BIM for Sustainability Analyses. International Journal of Construction Education and Research, 5, 276-292.

Bew, M., and Underwood, J., (2009) Delivering BIM to the UK Market, in: Handbook of research on building information modeling and construction informatics: concepts and technologies. IGI-Global, New York, 30-64.

Bloomberg, R. M., Burney, J. D., and Resnick, D. (2012). "BIM Guidelines". New York City Department of Design + Construction.

Cabinet Office, (2011) Government Construction Strategy.

Deutsch, R., (2011) BIM and Integrated Design: Strategies for architectural practice, John Wiley and Sons.

Eastman, C., Teicholz, P., Sacks, R., \& Liston, K. (2008) BIM Handbook: A Guide to Building Information Modelling for Owners, Managers, Designers, Engineers, and Contractors. John Wiley \& Sonic, Inc., Hoboken, New Jersey, pp. xi-xii, 13, 18-19. 
Eastman, C., Teicholz, P., Sacks, R., and Liston, K. (2011) "BIM Handbook - A Guide to Building Information Modeling for Owners, Managers, Designers, Engineers, and Contractors" Second Edition.

Hannon, J. J. (2007) Estimators' Functional Role Change with BIM. AACE International Transactions, 03.1-03.8.

Haque, M. E. \& Mishra, R. (2007) 5D virtual constructions: Designer/constructor's perspective. In: 10th international conference on Computer and information technology, 2729 Dec. 20072007 Dhaka, Bangladesh. 1-4.

Hardin, B., (2009) BIM and Construction Management: Proven tools, methods, and workflows. Wiley Publishing, Inc.

HM Government, (2012) Building Information Modelling. Industrial Strategy: government and industry in partnership. http://www.bis.gov.uk/assets/BISCore/economicsand statistics/docs/I/12-1140-industrial-strategy-uk-sector-analysis.pdf.

Howard R., and Bjork B. C., (2008) Building Information Modelling - expert views on standardization and Industry development. Advanced Engineering Information, 22, 271280.

Kraus, W. E., Watt, S. \& Larson, P. D. (2007) Challenges in Estimating Costs Using Building Information Modeling. AACE International Transactions, 01.1-01.3.

Lin, Q., Gao, T. and Wang, J. (2011) "Research on Application of BIM Technology in Construction Project", Computer Science and Service System (CSSS), International Conference, Nanjing.

McCuen, T. L. (2008) Scheduling, Estimating, and BIM: a Profitable Combination. AACE International Transactions, 1-8.

Mena, Á., López, F., Framiñan, J. M., Flores, F. \& Gallego, J. M. (2010) XPDRL project: Improving the project documentation quality in the Spanish architectural, engineering and construction sector. Automation in Construction, 19, 270-282.

Ministry of Justice, (2013) Early Adopters Project - HMYOI Cookham wood: New House Block and Education Building, BIM lessons learnt, Report Version 3.

Pan, W., and Sidwell, R (2011) Demystifying the cost barriers to offsite construction in the UK. "Construction Management and Economics", 29(11), 1081-1099.

Pennanen, A., Ballard, G. \& Haahtela, Y. (2011) Target costing and designing to targets in construction. Journal of Financial Management of Property and Construction, 16, 52-63.

RICS, (2014) Report for Royal Institution of Chartered Surveyors. www.rics.org/research.

Sylvester, K. E. \& Dietrich, C. (2010) Evaluation of Building Information Modeling (BIM) Estimating Methods in Construction Education. In: International conference of the 46th Annual ASC Conference, April 7-10, 20102010 Omaha, Nebraska, US. ASC.

Thurairajah, N., and Goucher, D., (2013). Advantages and Challenges of Using BIM: a Cost Consultancy's Perspective. 49th ASC Annual International Conference Proceedings.

Woo, J. H. (2007) BIM (Building Information Modeling) and Pedagogical Challenges. In: International Proceedings of the 43rd Annual ASC Conference, April 12 - 14, 20072007 Flagstaff, Arizona, US. ASC. 